\section{$\underset{\substack{\text { hommes } \\ \text { \& migrations }}}{ }$}

\section{Hommes \& migrations}

Revue française de référence sur les dynamiques

migratoires

$1302 \mid 2013$

Le Japon, pays d'immigration?

\title{
Yassaman Montazami, Le Meilleur des jours
}

Paris, Sabine Wespieser, 2012, 138 p., 15,00€.

\section{Mustapha Harzoune}

\section{Q OpenEdition \\ 1 Journals}

\section{Édition électronique}

URL : http://journals.openedition.org/hommesmigrations/2531

DOI : 10.4000/hommesmigrations.2531

ISSN : 2262-3353

\section{Éditeur}

Musée national de l'histoire de l'immigration

\section{Édition imprimée}

Date de publication : 1 avril 2013

Pagination : 197-198

ISBN : 978-2-919040-22-3

ISSN : 1142-852X

\section{Référence électronique}

Mustapha Harzoune, "Yassaman Montazami, Le Meilleur des jours », Hommes \& migrations [En ligne], 1302 | 2013, mis en ligne le 17 septembre 2013, consulté le 22 septembre 2020. URL : http:// journals.openedition.org/hommesmigrations/2531; DOI : https://doi.org/10.4000/ hommesmigrations.2531

Ce document a été généré automatiquement le 22 septembre 2020.

Tous droits réservés 


\title{
Yassaman Montazami, Le Meilleur des jours
}

Paris, Sabine Wespieser, 2012, 138 p., 15,00€.

\author{
Mustapha Harzoune
}

\section{RÉFÉRENCE}

Sabine Wespieser, Le Meilleur des jours, Paris, Sabine Wespieser, 2012, 138 p., 15,00 €.

1 Une lumière qui se retrouve dans le style de Yassaman Montazami : léger, drôle, vif, attendrissant.

2 Le fils de Rosa fut un prématuré, condamné à rejoindre le sort des autres enfants mortnés. Jusqu'à ce jour où, poussant enfin un cri, il s'éveille à la vie et inonde de bonheur le cœur de sa mère. En souvenir de cette journée exceptionnelle, elle le prénomme "Beyrouz", "le meilleur des jours" en persan.

3 Behrouz, en révolutionnaire digne de ce nom et grâce à maman Rosa, célébrissime et richissime auteure de livres de cuisine, ne travailla pas de sa vie entière, occupé qu'il était à la rédaction de sa thèse consacrée à Marx. Cette thèse, pour laquelle il s'exila en France à la fin des années 1960, fut la grande affaire de sa vie, pourtant elle ne vit jamais le jour. Insatiable de connaissances, l'homme, toujours, remit sur le métier son œuvre qui en devint virtuelle, à jamais. Personne ne connaîtra donc "la cause originaire de l'inégalité entre les hommes" et le monde ne deviendra pas "meilleur".

Qu'importe, Beyrouz a laissé davantage que des milliers de feuillets noircis en farsi ou les 3000 livres de sa bibliothèque. L'homme fut un être généreux, facétieux, hospitalier - pour l'opposition de gauche comme pour une aristocrate nostalgique du Shah -, un homme respectueux de tous, à commencer sa fille, qu'il considéra non comme une enfant mais comme "un sujet de plein droit doué d'un libre arbitre". Murmurant à l'occasion des vers de Hâfez: "Bois, car qui a vu comment s'achève l'œuvre du monde, s'est délivré prestement du chagrin et a pris la lourde coupe", il fut plus poète que militant. 
5 Les trente années de mariage avec Zahra, la "lunaire", furent simplement affectueuses. L'amour attendait, ailleurs. À Téhéran. Il s'appelait Bibi, Bibi la "solaire", qui au temps lointain de la faculté, après l'annonce des fiançailles de Beyrouz et Zahra, "se jeta dans le mariage comme on se lancerait dans le vide par une fenêtre". Avec Darius, Bibi et Beyrouz formeront un ménage à trois. La fantaisie de Beyrouz réussit à distraire l'époux frappé de neurasthénie depuis la Révolution islamique. Ensemble ils fument du haschish, ensemble ils conversent, ensemble ils lisent et commentent les poèmes de Hâfez, ensemble ils fredonnent et dansent sur des vieux tubes de Boney $\mathrm{M}$.

6 Comme chez Amin Maalouf (Les Désorientés), le retour de l'exilé annonce les retrouvailles avec les anciens camarades, les rescapés de "l'armée des ombres". Ici, la culpabilité domine: face à Bijan, "brisé" par cinq années d'emprisonnement et de tortures, "Beyrouz fut pris d'une gêne incommensurable. Il ne savait que lui dire, il n'osait le regarder. (...) Mon père se sentait soudain coupable de ne pas avoir été embastillé lui aussi. (...) Il aurait voulu fuir."

Le Meilleur des jours est une miniature littéraire dédiée à un homme rare et attachant, une sorte de saint laïc, à mi-chemin entre un personnage d'Albert Cossery et un bouddha rieur, n'était le physique, sans doute, de cet amateur de whisky et de canard à l'orange cuisiné les nuits d'insomnie et offert en guise de petit déjeuner à sa fille. 